\title{
Frequency of Gastro-Esophageal Reflux symptoms in Healthy Children Determined by MM GERD Questionnaire in Mexico: An Exploratory Study
}

\author{
Rogelio Ramses Hernandez-Pliego ${ }^{1}$ and Jose Ivan Rodriguez de Molina-Serrano ${ }^{*}$ \\ ${ }^{1} \mathrm{PhD}$ Instituto Politécnico Nacional, Mexico \\ ${ }^{2}$ Critical Care Division, Intensive Care Unit, Clinica Mexico and HGZ 11 IMSS Piedras Negras, Coahuila 26020, Mexico
}

${ }^{*}$ Corresponding author: Dr. Jose Ivan Rodriguez de Molina Serrano, Critical Care Division, Head of Intensive Care Unit, Clinica Mexico and HGZ 11 IMSS Piedras Negras, Coahuila 26020, Mexico, Tel: + 525525848735; E-mail: jirdems@gmail.com

Received date: February 26, 2020; Accepted date: March 05, 2019; Published date: March 12, 2020

Citation: Hernandez Pliego RR, De Molina Serrano JIR (2020) Frequency of Gastro-Esophageal Reflux symptoms in Healthy Children Determined by MM GERD Questionnaire in Mexico: An Exploratory Study. Arch Med Vol: 12 Iss: 2:4

Copyright: (C2020 Hernandez Pliego RR, et al. This is an open-access article distributed under the terms of the Creative Commons Attribution License, which permits unrestricted use, distribution, and reproduction in any medium, provided the original author and source are credited.

\section{Abstract}

Background: GERD is a common disorder in children representing an important cause of consultation. Questionnaires have been proposed as a useful tool for primary care medicine but also as a cost effective option. However, it's use still controversial in pediatric population. In this exploratory study, we have used the MM GERD Questionnaire in 2 elementary schools.

Objective: An exploratory study to evaluate the MM GERD questionnaire in children of 5-17 years old of 2 elementary schools in Mexico City.

Methods: A prospective, descriptive exploratory study including male and female children 5-17 years in which parents or tutors accept and sign ICF and willing to answer the 4 scale multi-dimensional GERD scale symptom (10 items), pain intensity scale (3 items); disability scale ( 3 items) and satisfaction scale ( 2 items).

Results: A total of 223 children were included with 123 male and 99 female with mean age of $8.64 \pm 2.7$, weight $32.94 \pm 14.17 \mathrm{~kg}$, height $1.30 \pm 0.17 \mathrm{mt}$ and $\mathrm{BMI}$ of 18.67 \pm 4.9. There was good construct validity among 4 scales measured with Pearson coefficient. The inter-item consistency (Cronbach's co-efficient alpha) for the symptoms items, pain intensity items, disability items and satisfaction items were $0.41,0.78,0.87$ and 0.4 , respectively, demonstrating adequate reliability of the measure.

Conclusion: MM GERD is a not a reliable questionnaire to explore the presence of upper gastrointestinal symptoms in healthy children from 5-17 years old. Thus several limitations, it is necessary to assess language, methodological and clinical validation of MM GERD to extrapolate these results into clinical practice.
Keywords: Gastroesophageal Reflux Disease (GERD); Multidimensional Measure for Gastroesophageal Reflux Disease (MM GERD); Children; Upper gastrointestinal symptoms

\section{Introduction}

Gastroesophageal Reflux Disease (GERD) is a common gastrointestinal disorder. In children is a common disease and the prevalence of symptoms varies with age [1-4]. GERD represents up to $65 \%$ of the daily practice of the general physician or pediatrician [5]. In children, it is important to differentiate physiologic reflux from GERD. GERD occurs when the reflux of stomach contents, whether solid or liquid, causes troublesome symptoms and or complications which affect quality of life [6]. GERD diagnosis in children is confirmed by a detailed clinical history and physical examination but specific tests such a 24 hour pH-metry and or impedanciometry sometimes are required for confirmation [7].

The use of questionnaires to identify symptoms of GERD in adults has been well established [8-10] and also documented in children [11-15]. However its applicability in pediatric population have some concerns [16] including its usefulness in young children and infants where it is impossible for them to describe specific symptoms objectively. Questionnaires for GERD have some advantages such as acceptable sensitivity and specificity, low cost, can be applied at doctor office and does not require specialized training or certifications for application. Different authors have used different questionnaires for GERD symptoms identification depending on age, symptom presentation, person who responds (caregiver or tutor) and other factors [11-15]. Malaty et al. [17] developed the Multidimensional Measure for gastroesophageal reflux disease (MM GERD) questionnaire on 2008 including children population of 4-18 years old. The MM GERD assess symptoms associated with GERD and other important dimensions, daily and weekend affectation and others, usually associated when GERD symptoms are present with very acceptable reliability 
and applicability. The MM GERD has four components or scales: symptoms, pain intensity, sense of well-being (health satisfaction) and disability. Thus, the MM GERD could be a potential diagnose instrument for GERD in children as initial approach by primary care physician and/or when specific and invasive laboratory tests are not available [17].

In this study, we assess the MM GERD to measure GERD symptoms in healthy children of 2 different elementary schools of Mexico City. Furthermore, we evaluate the reliability of MM GERD on this population.

\section{Methods}

After approval of the Ethics Committee of our Institution, we proceed to invite parents of elementary schools to participate in the study. We obtained ICF of parents or tutors of children willing to participate in the study.

We included all accessible population of infants and children, male and female from 5 to 17 years old whose both parents or tutors previously signed the ICF willing to participate and completed all measures of the study. Exclusion criteria were all cases with current or 14 day previous treatment with any acid suppression drugs, voluntary discontinuation or any concomitant diagnosed disease. Elimination criteria were all cases with less than $80 \%$ of study measures were not included for analysis. All procedures were performed in compliance with good clinical practices (GCPs), International Conference of Harmonization (ICH) and Reglamento de la Ley General de Salud en Materia de Investigación para la Salud.

Data recollection was performed at the facilities of 2 different elementary SEP schools of Mexico City during the period of 13-20 of July, 2015.

Dates were recollected by 2 medical doctors previously trained on the questionnaire assessment. First, we explained all procedures to each participant. All questionnaires were unique and numbered independently. All questionnaires were fulfilled individually in a specific room separately with each participant in order to get more accuracy on the responses. Children 5-10 years were accompanied by a parent or a school representative for questionnaire competition and children from 11-18 years were capable for questionnaire competition and were accompanied only by a school representative. Once the questionnaire was completed, we performed anthropometric measures to each participant using the Omron HBF-514c weighing machine (Figure 1). After completed all the study measures of each sheet we did the transcription into an electronic spreadsheet with specific encoding using the Software Stata 12 , 8th edition.

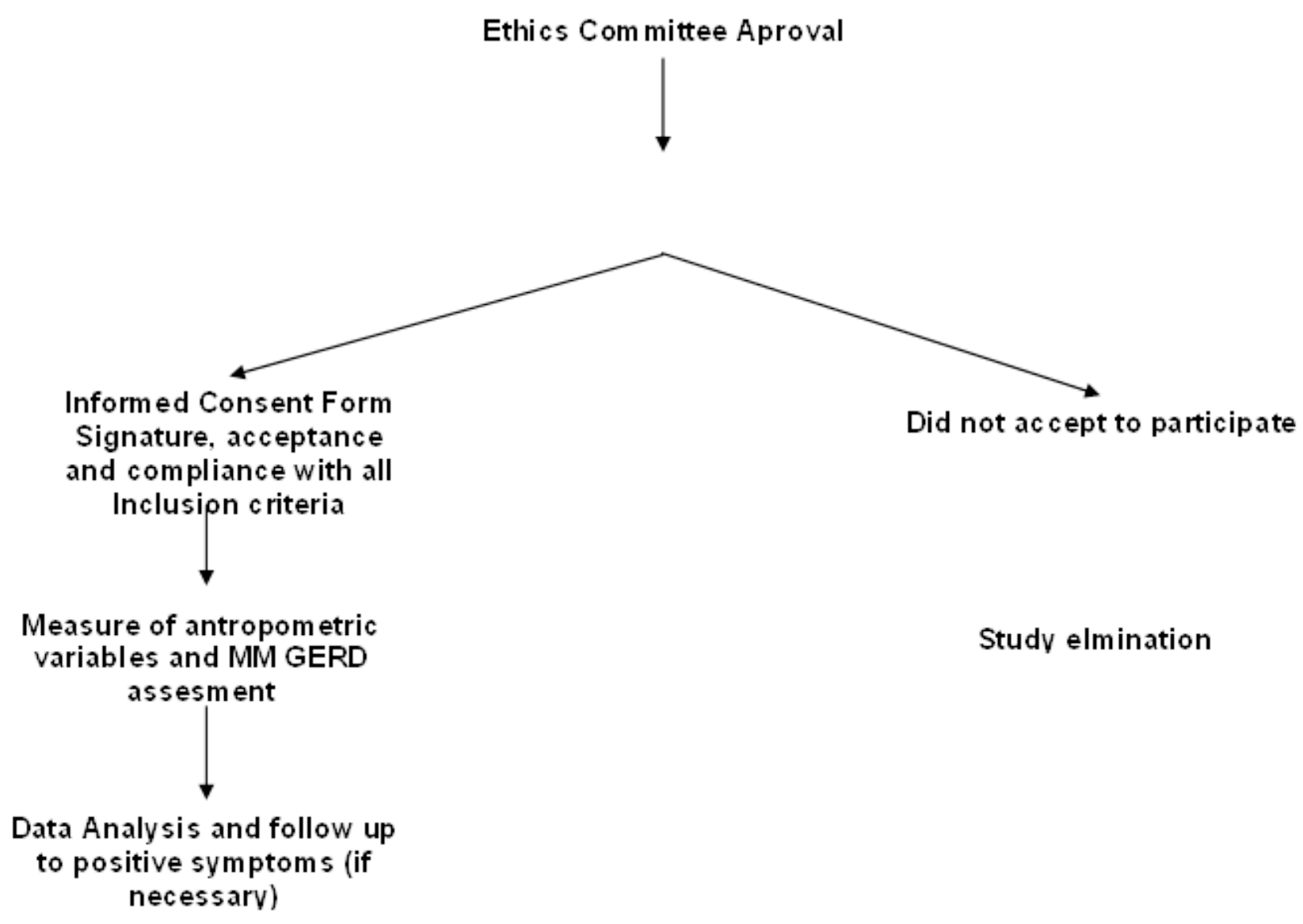

Figure 1 Flow diagram. 
The MM GERD was translated into local language but not validated for this study. All scales and dimensions were applied as described by Malaty et al. according to 4 different multidimensional scales described below:

\section{Symptoms scale}

Symptoms scale consists in 10 items of the range of GERDrelated symptoms (heartburn, regurgitation, nausea/vomiting, epigastric pain/ abdominal pain, dysphagia/difficulty swallowing, painful swallowing, burping/belching, chest pain, bloating, weight loss). Each symptom is rated from 1 to 5, where 1 represents no problem and 5 represents a very severe problem.

\section{Pain intensity scale}

Pain Intensity Scale consist in three items; first is the WongBaker Face scale that is used to rate the pain now; 0 represents a very happy face and 5 represents tearful face/hurts; second is rating the Pain intensity over the previous 3 months measured on $0-10$ scales ( $0=$ no pain; $10=$ pain as bad as it could be) and third is Pain discomfort over a period of 3 months measured on $0-10$ scales $(0=$ no pain; $10=$ pain as bad as it could be); all three are then summed to give a final pain intensity score.

\section{Disability scale}

Disability scale is derived from 3 items. The first item rates how the child's abdominal pain interfered with her/his school attendance during the previous 3 months measured on a 10 point scale $(0=$ never missed a school day to 10 where a child missed 10 or more days), the second and third items rate how the child's abdominal pain interfered with daily and weekly activities, respectively, during the previous 3 months measured on $0-10$ scales ( $0=$ never and $10=$ always).

\section{Satisfaction scale}

This scale consisted of two items that evaluated the overall GERD symptoms. The two items were how concerned and worried the child is in regard to the level of GERD symptoms. Both items included responses to questions measured on 1-5 point scales (1=definitely true that I feel concerned (first item) or worried (second item) with my health with regard to my GERD symptoms and $5=$ definitely false).

Once the MM GERD was performed to the sample of this study, we proceed to evaluate the study database, including or eliminating all data according to inclusion/ exclusion criteria.

\section{Statistical analysis}

The primary objective of the present study was to evaluate the reliability of MM GERD in healthy pediatric population as an exploratory analysis.

The proposed statistical analysis for this study was performed in order to test reliability of the MM GERD including the Pearson coefficient, Cronbach alpha coefficient.
The internal consistency was calculated for the four scales: the symptoms scale, pain intensity scale, disability scale and satisfaction scale. We calculate the Pearson coefficient (Table 1) and the multivariate analysis using the alpha Cronbach coefficient (Table 2).

Table 1 Pearson correlations for demographic characteristics.

\begin{tabular}{|l|l|l|l|l|}
\hline Variables & Age & Weight & Height & BMI \\
\hline Age & 1 & & & \\
\hline Weight & $0.7107^{*}$ & 1 & & \\
\hline Height & $0.7165^{*}$ & $0.8660^{*}$ & 1 & \\
\hline BMI & $0.4941^{*}$ & $0.8306^{*}$ & $0.4827^{*}$ & 1 \\
\hline
\end{tabular}

Table 2 Multivariate analysis of the MM GERD symptoms scales.

\begin{tabular}{|l|l|l|l|l|}
\hline Scale & Symptom & Disability & Pain & Satisfaction \\
\hline a Cronbach & 0.4141 & 0.7864 & 0.8718 & 0.4428 \\
\hline
\end{tabular}

\section{Results}

A total of 373 parents or tutors of 2 different schools accepted to participate in this study during July 2015. However only 223 parents or tutors (59.7\%) signed the ICF and were included in the study. A total of 150 parents or tutors $(40.3 \%)$ were excluded of this study (Figure 2). On the first school, (school A) $n=95$ subjects were included and on the second school (school B) $n=128$ subjects were included in this study.

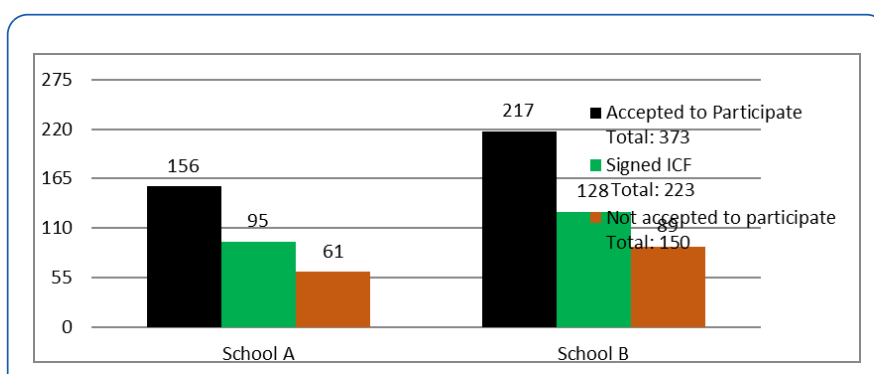

Figure 2 Subjects included in the study.

According to the study procedures we measure anthropometric parameters of each subject whose comply with all inclusion and with any exclusion criteria including age, height and BMI (Table 3) and after that we applied the MM GERD questionnaire to all subjects. A total of 124 subjects (55.61\%) were male and 99 (44.39\%) were female. Age, weight, height and BMI of subjects who participated were 8.64 \pm 2.7 years, $32.94 \pm 14.17 \mathrm{~kg}, 1.30 \pm 0.17 \mathrm{mts}$ and $18.67 \pm 4.9$ $\left(\mathrm{kg} / \mathrm{m}^{2}\right)$ respectively.

Table 3 Demographic characteristics of study population.

\begin{tabular}{|l|l|l|l|l|}
\hline Variables & Average & Range & Male & Female \\
\hline Age (years) & $8.64 \pm 2.7$ & May-15 & 8.63 & 8.64 \\
\hline
\end{tabular}




\begin{tabular}{|l|l|l|l|l|}
\hline Weight $(\mathrm{kg})$ & $32.94 \pm 14.17$ & $10.30-82$ & 32.98 & 32.93 \\
\hline Height $(\mathrm{mts})$ & $1.30 \pm 0.17$ & $0.78-1.75$ & 1.30 & 1.30 \\
\hline BMI $\left(\mathrm{kg} / \mathrm{m}^{2}\right)$ & $18.67 \pm 4.9$ & $10.18-50.79$ & 18.68 & 18.67 \\
\hline
\end{tabular}

As mentioned before, MM GERD consists in a 4 multidimensional scale questionnaire divided in 1) symptom scale, 2) Pain Intensity Scale, 3) Pain Intensity Scale and 4) Satisfaction scale. We obtained the following results according to each scale.
On the Symptom scale (Table 4), most of responses were negative, however we found positive responses on scale symptom on 6 different items suggesting the presence of gastrointestinal upper symptoms in the past 7 days. The most frequent symptoms found in the study population were regurgitation (20.6\%) and heartburn (15.7\%). Also other symptoms were present such as nausea/ vomiting (8.5\%), belching (7.7\%), bloating (5.8\%) and dysphagia (7.3\%). More positive answers in the symptom scale were found in male $(29.7 \%)$ vs female $(23.8 \%)$.

Table 4 Symptom scale results of the study.

\begin{tabular}{|c|c|c|c|c|c|c|c|c|c|c|c|c|}
\hline Symptoms & Age & Gender & 1 & $\%$ & 2 & $\%$ & 3 & $\%$ & 4 & $\%$ & 5 & $\%$ \\
\hline \multirow{4}{*}{ Heartburn } & \multirow{2}{*}{$5-9$} & $\mathrm{~F}$ & 65 & $29.10 \%$ & 5 & $2.20 \%$ & 2 & $0.90 \%$ & 1 & $0.40 \%$ & 0 & $0.00 \%$ \\
\hline & & $M$ & 63 & $28.30 \%$ & 9 & $4.00 \%$ & 4 & $1.80 \%$ & 0 & $0.00 \%$ & 0 & $0.00 \%$ \\
\hline & \multirow{2}{*}{$10-15$} & $\mathrm{~F}$ & 20 & $9.00 \%$ & 5 & $2.20 \%$ & 0 & $0.00 \%$ & 1 & $0.40 \%$ & 0 & $0.00 \%$ \\
\hline & & $M$ & 40 & $17.90 \%$ & 4 & $1.80 \%$ & 3 & $1.30 \%$ & 1 & $0.40 \%$ & 0 & $0.00 \%$ \\
\hline \multirow{4}{*}{ Regurgitation } & \multirow{2}{*}{$5-9$} & $\mathrm{~F}$ & 60 & $26.90 \%$ & 12 & $5.40 \%$ & 1 & $0.40 \%$ & 0 & $0.00 \%$ & 0 & $0.00 \%$ \\
\hline & & M & 62 & $27.80 \%$ & 14 & $6.30 \%$ & 0 & $0.00 \%$ & 0 & $0.00 \%$ & 0 & $0.00 \%$ \\
\hline & \multirow{2}{*}{$10-15$} & $\mathrm{~F}$ & 20 & $9.00 \%$ & 5 & $2.20 \%$ & 0 & $0.00 \%$ & 1 & $0.40 \%$ & 0 & $0.00 \%$ \\
\hline & & M & 35 & $15.70 \%$ & 11 & $4.90 \%$ & 2 & $0.90 \%$ & 0 & $0.00 \%$ & 0 & $0.00 \%$ \\
\hline \multirow[b]{4}{*}{ Nausea/ Vomiting } & \multirow{2}{*}{$5-9$} & $\mathrm{~F}$ & 62 & $27.80 \%$ & 10 & $4.50 \%$ & 1 & $0.40 \%$ & 0 & $0.00 \%$ & 0 & $0.00 \%$ \\
\hline & & M & 73 & $32.70 \%$ & 2 & $0.90 \%$ & 1 & $0.40 \%$ & 0 & $0.00 \%$ & 0 & $0.00 \%$ \\
\hline & & $\mathrm{F}$ & 24 & $10.80 \%$ & 2 & $0.90 \%$ & 0 & $0.00 \%$ & 0 & $0.00 \%$ & 0 & $0.00 \%$ \\
\hline & & $M$ & 45 & $20.20 \%$ & 2 & $0.90 \%$ & 1 & $0.40 \%$ & 0 & $0.00 \%$ & 0 & $0.00 \%$ \\
\hline \multirow{4}{*}{$\begin{array}{l}\text { Dysphagia/ } \\
\text { Difficulty }\end{array}$} & \multirow{2}{*}{$5-9$} & $\mathrm{~F}$ & 73 & $32.70 \%$ & 0 & $0.00 \%$ & 0 & $0.00 \%$ & 0 & $0.00 \%$ & 0 & $0.00 \%$ \\
\hline & & $M$ & 76 & $34.10 \%$ & 0 & $0.00 \%$ & 0 & $0.00 \%$ & 0 & $0.00 \%$ & 0 & $0.00 \%$ \\
\hline & \multirow{2}{*}{$10-15$} & $\mathrm{~F}$ & 25 & $11.20 \%$ & 1 & $0.40 \%$ & 0 & $0.00 \%$ & 0 & $0.00 \%$ & 0 & $0.00 \%$ \\
\hline & & $M$ & 45 & $20.20 \%$ & 3 & $1.30 \%$ & 0 & $0.00 \%$ & 0 & $0.00 \%$ & 0 & $0.00 \%$ \\
\hline \multirow{4}{*}{ Burping/ Belching } & \multirow{2}{*}{$5-9$} & $\mathrm{~F}$ & 67 & $30.00 \%$ & 4 & $1.80 \%$ & 0 & $0.00 \%$ & 0 & $0.00 \%$ & 0 & $0.00 \%$ \\
\hline & & M & 71 & $31.80 \%$ & 5 & $2.20 \%$ & 0 & $0.00 \%$ & 0 & $0.00 \%$ & 0 & $0.00 \%$ \\
\hline & \multirow{2}{*}{$10-15$} & $\mathrm{~F}$ & 25 & $11.20 \%$ & 1 & $0.40 \%$ & 1 & $0.40 \%$ & 0 & $0.00 \%$ & 0 & $0.00 \%$ \\
\hline & & M & 44 & $19.70 \%$ & 2 & $0.90 \%$ & 2 & $0.90 \%$ & 0 & $0.00 \%$ & 0 & $0.00 \%$ \\
\hline \multirow{4}{*}{ Bloating } & \multirow{2}{*}{$5-9$} & $\mathrm{~F}$ & 71 & $31.80 \%$ & 0 & $0.00 \%$ & 0 & $0.00 \%$ & 0 & $0.00 \%$ & 0 & $0.00 \%$ \\
\hline & & $M$ & 71 & $31.80 \%$ & 0 & $0.00 \%$ & 0 & $0.00 \%$ & 0 & $0.00 \%$ & 0 & $0.00 \%$ \\
\hline & \multirow{2}{*}{$10-15$} & $\mathrm{~F}$ & 24 & $10.80 \%$ & 0 & $0.00 \%$ & 0 & $0.00 \%$ & 0 & $0.00 \%$ & 0 & $0.00 \%$ \\
\hline & & M & 44 & $19.70 \%$ & 0 & $0.00 \%$ & 0 & $0.00 \%$ & 0 & $0.00 \%$ & 0 & $0.00 \%$ \\
\hline \multirow{4}{*}{ Epigastric Pain/ } & \multirow{2}{*}{$5-9$} & $\mathrm{~F}$ & 73 & $32.70 \%$ & 0 & $0.00 \%$ & 0 & $0.00 \%$ & 0 & $0.00 \%$ & 0 & $0.00 \%$ \\
\hline & & $M$ & 76 & $34.10 \%$ & 0 & $0.00 \%$ & 0 & $0.00 \%$ & 0 & $0.00 \%$ & 0 & $0.00 \%$ \\
\hline & \multirow{2}{*}{$10-15$} & $\mathrm{~F}$ & 26 & $11.70 \%$ & 0 & $0.00 \%$ & 0 & $0.00 \%$ & 0 & $0.00 \%$ & 0 & $0.00 \%$ \\
\hline & & M & 48 & $21.50 \%$ & 0 & $0.00 \%$ & 0 & $0.00 \%$ & 0 & $0.00 \%$ & 0 & $0.00 \%$ \\
\hline \multirow{2}{*}{ Chest pain } & \multirow{2}{*}{$5-9$} & $\mathrm{~F}$ & 73 & $32.70 \%$ & 0 & $0.00 \%$ & 0 & $0.00 \%$ & 0 & $0.00 \%$ & 0 & $0.00 \%$ \\
\hline & & $M$ & 76 & $34.10 \%$ & 0 & $0.00 \%$ & 0 & $0.00 \%$ & 0 & $0.00 \%$ & 0 & $0.00 \%$ \\
\hline
\end{tabular}




\begin{tabular}{|c|c|c|c|c|c|c|c|c|c|c|c|c|}
\hline & \multirow{2}{*}{$10-15$} & $\mathrm{~F}$ & 26 & $11.70 \%$ & 0 & $0.00 \%$ & 0 & $0.00 \%$ & 0 & $0.00 \%$ & 0 & $0.00 \%$ \\
\hline & & $M$ & 48 & $21.50 \%$ & 0 & $0.00 \%$ & 0 & $0.00 \%$ & 0 & $0.00 \%$ & 0 & $0.00 \%$ \\
\hline \multirow{4}{*}{ Painful swallowing } & \multirow{2}{*}{$5-9$} & $\mathrm{~F}$ & 73 & $32.70 \%$ & 0 & $0.00 \%$ & 0 & $0.00 \%$ & 0 & $0.00 \%$ & 0 & $0.00 \%$ \\
\hline & & $M$ & 76 & $34.10 \%$ & 0 & $0.00 \%$ & 0 & $0.00 \%$ & 0 & $0.00 \%$ & 0 & $0.00 \%$ \\
\hline & \multirow{2}{*}{$10-15$} & $\mathrm{~F}$ & 26 & $11.70 \%$ & 0 & $0.00 \%$ & 0 & $0.00 \%$ & 0 & $0.00 \%$ & 0 & $0.00 \%$ \\
\hline & & M & 48 & $21.50 \%$ & 0 & $0.00 \%$ & 0 & $0.00 \%$ & 0 & $0.00 \%$ & 0 & $0.00 \%$ \\
\hline \multirow{4}{*}{ weight loss } & \multirow{2}{*}{$5-9$} & $\mathrm{~F}$ & 73 & $32.70 \%$ & 0 & $0.00 \%$ & 0 & $0.00 \%$ & 0 & $0.00 \%$ & 0 & $0.00 \%$ \\
\hline & & $M$ & 76 & $34.10 \%$ & 0 & $0.00 \%$ & 0 & $0.00 \%$ & 0 & $0.00 \%$ & 0 & $0.00 \%$ \\
\hline & \multirow{2}{*}{$10-15$} & $\mathrm{~F}$ & 26 & $11.70 \%$ & 0 & $0.00 \%$ & 0 & $0.00 \%$ & 0 & $0.00 \%$ & 0 & $0.00 \%$ \\
\hline & & $M$ & 48 & $21.50 \%$ & 0 & $0.00 \%$ & 0 & $0.00 \%$ & 0 & $0.00 \%$ & 0 & $0.00 \%$ \\
\hline
\end{tabular}

The Pain intensity scale (Table 5) has 3 different components: Pain intensity, Wong Baker Face and discomfort scale. We found a total of $87.89 \%$ subjects who had negative response to any of the different items of pain intensity scale. However, 81 subjects (12.11\%) of the population had positive responses to any of the items of the pain intensity scale suggesting variable intensity of symptoms during the last week (Table 5).

Table 5 Pain Intensity.

\begin{tabular}{|l|l|l|l|l|}
\hline Pain intensity & Frequency & Male & Female & $\%$ \\
\hline 0 & 202 & 112 & 90 & $90.58 \%$ \\
\hline 1 & 11 & 6 & 5 & $4.93 \%$ \\
\hline 2 & 3 & 1 & 2 & $1.35 \%$ \\
\hline 3 & 2 & 2 & 0 & $0.90 \%$ \\
\hline
\end{tabular}

\begin{tabular}{|l|l|l|l|l|}
\hline 4 & 1 & 0 & 1 & $0.45 \%$ \\
\hline 5 & 1 & 0 & 1 & $0.45 \%$ \\
\hline 6 & 0 & 0 & 0 & $0.00 \%$ \\
\hline 7 & 1 & 0 & 1 & $0.45 \%$ \\
\hline 8 & 0 & 0 & 0 & $0.00 \%$ \\
\hline 9 & 0 & 0 & 0 & $0.00 \%$ \\
\hline 10 & 2 & 2 & 0 & $0.90 \%$ \\
\hline
\end{tabular}

The Wonk Baker Face scale is a very easy graphic pain intensity scale in which the subject the face that best describe how he/she were feeling. On this scale we found a high proportion of with negative responses (81.8\%) and only 32 positive responses (18.2\%) to this scale suggesting affectation during the 7 previous days (Table 6).

Table 6 Wonk Baker Face scale results on the study population.

\begin{tabular}{|c|c|c|c|c|c|c|c|c|c|c|c|c|c|c|}
\hline Symptom & Age & Gender & 0 & $\%$ & 1 & $\%$ & 2 & $\%$ & 3 & $\%$ & 4 & $\%$ & 5 & $\%$ \\
\hline \multirow{4}{*}{$\begin{array}{l}\text { Wonk } \\
\text { Face }\end{array}$} & \multirow{2}{*}{$5-9$} & $\mathrm{~F}$ & 64 & $28.7 \%$ & 2 & $0.90 \%$ & 4 & $1.80 \%$ & 1 & $0.40 \%$ & 1 & $0.40 \%$ & 1 & $0.40 \%$ \\
\hline & & M & 62 & $27.8 \%$ & 7 & $3.10 \%$ & 5 & $2.20 \%$ & 1 & $0.40 \%$ & 1 & $0.40 \%$ & 0 & $0.00 \%$ \\
\hline & \multirow{2}{*}{$10-15$} & $\mathrm{~F}$ & 19 & $8.5 \%$ & 2 & $0.90 \%$ & 3 & $1.30 \%$ & 1 & $0.40 \%$ & 0 & $0.00 \%$ & 1 & $0.40 \%$ \\
\hline & & M & 36 & $16.1 \%$ & 7 & $3.10 \%$ & 4 & $1.80 \%$ & 0 & $0.00 \%$ & 1 & $0.40 \%$ & 0 & $0.00 \%$ \\
\hline
\end{tabular}

On the Pain discomfort scale we obtained a 91.93\% (205 subjects) of negative responses and only $8.07 \%$ of positive response to this scale suggesting affectation during the 7 previous days (Table 7). A total of 3 subjects (1.35\%) had severe discomfort related to their upper gastrointestinal symptoms on the past 7 days highlight this condition.

Table 7 Pain discomfort scale results on the study population.

\begin{tabular}{|l|l|l|l|l|}
\hline Discomfort & Frequency & Male & Female & $\%$ \\
\hline 0 & 205 & 116 & 89 & $91.93 \%$ \\
\hline 1 & 9 & 3 & 6 & $4.04 \%$ \\
\hline 2 & 3 & 1 & 2 & $1.35 \%$ \\
\hline
\end{tabular}




\begin{tabular}{|l|l|l|l|l|}
\hline 3 & 2 & 1 & 1 & $0.90 \%$ \\
\hline 4 & 1 & 1 & 0 & $0.45 \%$ \\
\hline 5 & 0 & 0 & 0 & $0.00 \%$ \\
\hline 6 & 0 & 0 & 0 & $0.00 \%$ \\
\hline 7 & 0 & 0 & 0 & $0.00 \%$ \\
\hline 8 & 0 & 0 & 0 & $0.00 \%$ \\
\hline 9 & 0 & 0 & 0 & $0.00 \%$ \\
\hline 10 & 3 & 2 & 1 & $1.35 \%$ \\
\hline
\end{tabular}

On the disability scale (Table 8) we found a total of 16 subjects who had positive response $(16.2 \%)$ to any of the different items of pain intensity scale suggesting symptoms affect their regular activities, weekend activities or missed one or more school days.

Table 8 Disability scale results of the study population.

\begin{tabular}{|c|c|c|c|c|c|c|c|c|c|c|c|}
\hline Symptoms & Age & Gender & 0 & $\%$ & 1 & $\%$ & 2 & $\%$ & 3 & $\%$ & 4 \\
\hline \multirow{4}{*}{$\begin{array}{l}\text { Her/his school attendance during the } \\
\text { previous }\end{array}$} & \multirow{2}{*}{$5-9$} & $\mathrm{~F}$ & 73 & $32.70 \%$ & 0 & $0.00 \%$ & 0 & $0.00 \%$ & 0 & $0.0 \%$ & 0 \\
\hline & & $M$ & 76 & $34.10 \%$ & 0 & $0.00 \%$ & 0 & $0.00 \%$ & 0 & $0.0 \%$ & 0 \\
\hline & \multirow[b]{2}{*}{$10-15$} & $\mathrm{~F}$ & 24 & $10.80 \%$ & 2 & $0.90 \%$ & 0 & $0.00 \%$ & 0 & $0.0 \%$ & 0 \\
\hline & & M & 46 & $20.60 \%$ & 1 & $0.40 \%$ & 1 & $0.40 \%$ & 0 & $0.0 \%$ & 0 \\
\hline \multirow{4}{*}{ Pain interfered with daily } & \multirow{2}{*}{$5-9$} & $\mathrm{~F}$ & 70 & $31.40 \%$ & 2 & $0.90 \%$ & 1 & $0.40 \%$ & 0 & $0.0 \%$ & 0 \\
\hline & & M & 75 & $33.60 \%$ & 1 & $0.40 \%$ & 0 & $0.00 \%$ & 0 & $0.0 \%$ & 0 \\
\hline & \multirow[b]{2}{*}{$10-15$} & $\mathrm{~F}$ & 24 & $10.80 \%$ & 2 & $0.90 \%$ & 0 & $0.00 \%$ & 0 & $0.0 \%$ & 0 \\
\hline & & $M$ & 47 & $21.10 \%$ & 0 & $0.00 \%$ & 1 & $0.40 \%$ & 0 & $0.0 \%$ & 0 \\
\hline \multirow{4}{*}{ Pain interfered } & \multirow{2}{*}{$5-9$} & $\mathrm{~F}$ & 70 & $31.40 \%$ & 2 & $0.90 \%$ & 1 & $0.40 \%$ & 0 & $0.0 \%$ & 0 \\
\hline & & $M$ & 75 & $33.60 \%$ & 1 & $0.40 \%$ & 0 & $0.00 \%$ & 0 & $0.0 \%$ & 0 \\
\hline & \multirow[b]{2}{*}{$10-15$} & $\mathrm{~F}$ & 26 & $11.70 \%$ & 0 & $0.00 \%$ & 0 & $0.00 \%$ & 0 & $0.0 \%$ & 0 \\
\hline & & $M$ & 47 & $21.10 \%$ & 0 & $0.00 \%$ & 0 & $0.00 \%$ & 0 & $0.0 \%$ & 1 \\
\hline
\end{tabular}

On the satisfaction scale (Table 9) we found a total of 16 subjects who had positive response $(16.2 \%)$ to any of the different items of pain intensity scale suggesting symptoms

affect their regular activities, weekend activities or missed one or more school days.

Table 9 Satisfaction scale results of the study population.

\begin{tabular}{|c|c|c|c|c|c|c|c|c|c|c|c|c|}
\hline Symptoms & Age & Gender & 1 & $\%$ & 2 & $\%$ & 3 & $\%$ & 4 & $\%$ & 5 & $\%$ \\
\hline \multirow{4}{*}{ Worried } & \multirow{2}{*}{$5-9$} & $\mathrm{~F}$ & 0 & $0.00 \%$ & 1 & $0.40 \%$ & 1 & $0.4 \%$ & 0 & $0.00 \%$ & 71 & $31.80 \%$ \\
\hline & & $M$ & 0 & $0.00 \%$ & 0 & $0.00 \%$ & 0 & $0.0 \%$ & 1 & $0.40 \%$ & 75 & $33.60 \%$ \\
\hline & \multirow{2}{*}{$10-15$} & $\mathrm{~F}$ & 0 & $0.00 \%$ & 0 & $0.00 \%$ & 1 & $0.4 \%$ & 2 & $0.90 \%$ & 23 & $10.30 \%$ \\
\hline & & $M$ & 0 & $0.00 \%$ & 1 & $0.40 \%$ & 0 & $0.0 \%$ & 0 & $0.00 \%$ & 47 & $21.10 \%$ \\
\hline \multirow{4}{*}{ Concerned } & \multirow{2}{*}{$5-9$} & $\mathrm{~F}$ & 0 & $0.00 \%$ & 0 & $0.00 \%$ & 1 & $0.4 \%$ & 0 & $0.00 \%$ & 72 & $32.30 \%$ \\
\hline & & $M$ & 0 & $0.00 \%$ & 0 & $0.00 \%$ & 1 & $0.0 \%$ & 0 & $0.00 \%$ & 75 & $33.60 \%$ \\
\hline & \multirow{2}{*}{$10-15$} & $F$ & 0 & $0.00 \%$ & 0 & $0.00 \%$ & 0 & $0.4 \%$ & 1 & $0.40 \%$ & 25 & $11.20 \%$ \\
\hline & & $M$ & 0 & $0.00 \%$ & 1 & $0.40 \%$ & 0 & $0.0 \%$ & 0 & $0.00 \%$ & 47 & $21.10 \%$ \\
\hline
\end{tabular}




\section{Discussion}

GERD is common disease among pediatric and adult population [18]. The use of questionnaires for diagnosis of GERD has been common practice in adults and their use has also been referred in children. Initial publications on the use of questionnaires in children were performed by the group Orenstein University of Pittsburgh. In one of these studies the prevalence of regurgitation was $40 \%$ in healthy children [11]. Since then, several works were published with different study objectives include measuring the prevalence or frequency of GERD and/or upper gastrointestinal symptoms through different questionnaires. Other had evaluated the impact of symptoms as well as validation in different languages.

In this study we assessed the MM GERD in a healthy pediatric population of 5-18 years of a specific region of Mexico City in order to identify subjects with symptoms of gastroesophageal reflux. Unlike other GERD questionnaires mentioned in which evaluate isolated questions, the MM GERD developed by Malaty et al. has the advantage that it is multidimensional, representing the inclusion of a greater number of questions or items that may be included as part of the clinical manifestations of GERD. While only MM GERD was recommended by Malaty for use in clinical studies, in this study, we observed poor validity and reliability in the study population.

An advantage of the MM GERD consists on its validation on age range of 4-18 years unlike other questionnaires which are limited to infants, younger children or caregivers [11-15]. This can have an impact on the implementation of a single questionnaire for this age range and avoid the use of one or more questionnaires with different clinical applications. But this also represents a limitation of MM GERD because it can only be used in children over 4 years to respond to specific symptoms such as regurgitation, heartburn, chest pain, etc.

Malaty et al. performed a cross sectional population based study in which they recruited children 4-18 years obtaining very good reliability and validity suggesting the MM GERD can be useful to identify GERD symptoms in children. In this study we obtained poor interconsistency ( Cronbach 0.41, 0.78, 0.87, 0.44 ) on the 4 scales suggesting symptoms can be measured with reliability in this population.

As described in other studies using questionnaires for upper gastrointestinal symptom identification, the most frequent symptoms were regurgitation and heartburn but also other symptoms were present such as nausea/ vomiting, belching, bloating and dysphagia. In this study more positive answers to symptoms were found in male $[11,14,15]$

According to our findings, the disability scale symptoms more likely appear on weekends $s$ when children most of the times are under parents care which may be associated with nutritional and hygienic habits during weekends, however this was not confirmed in this study.

GERD symptom identification and diagnosis by a single questionnaire remains a controversial topic due to different outcomes, languages and variations within pediatric age intervals.

Several limitations were present in this exploratory study, we did not perform validation into native spanish language (only translation) of the MM GERD and this may influence on the results obtained, also our findings were not confirmed by another laboratory test such as $\mathrm{pH}$-metry or impedanciometry which may be helpful to correlate positive answers and symptoms with a gold standard diagnosis tool. Also we did not performed sensitivity and specificity analyses for this test.

\section{Conclusion}

In this exploratory study, the MM GERD is not a reliable questionnaire to explore the presence of upper gastrointestinal symptoms in healthy children from 5-17 years old. Thus several limitations, there is still an unmet need of an effective outcome measure for GERD in primary care medicine, it is necessary to assess language, methodological and clinical validation of MM GERD or other tools in order to extrapolate this results into clinical practice.

\section{Acknowledgements}

This study was partially supported by Consejo Nacional de Ciencia y Tecnología (CONACYT, México) and Sistema de Administración de Programas y Proyectos de Investigación (SIP/IPN).

\section{Authors Disclaimers and Funding}

- RRHP is employee for AstraZeneca Mexico, Medical Affairs Department.

- JAB is employee for Takeda Pharmaceuticals Mexico, Medical Affairs Department.

- LAR does not declare any conflict of interest.

- This study did not receive any support by Pharmaceutical Industry.

\section{References}

1. Baird DC, Harker DJ, Karmes AS (2015) Diagnosis and treatment of gastroesophageal reflux in infants and children. Am Fam Physician 92: 705-714.

2. Campanozzi A, Boccia G, Pensabene L, Panetta F, Marseglia A, et al. (2009) Prevalence and natural history of gastroesophageal reflux: Pediatric prospective survey. Pediatrics 123: 779-783.

3. Huerta-Iga FM1, Tamayo-de la Cuesta JL, Noble-Lugo A, RemesTroche JM, Valdovinos-Díaz MA (2012) The Mexican consensus on gastroesophageal reflux disease. Part I. Rev Gastroenterol Mex. 77: 193-213.

4. Vakil N1, van Zanten SV, Kahrilas P, Dent J, Jones R, et al. (2006) The Montreal definition and classification of gastroesophageal reflux disease: A global evidence-based consensus. Am J Gastroenterol. 101: 1900-1920.

5. Nelson SP, Chen EH, Syniar GM, Christoffel KK (1998) One-year follow-up of symptoms of gastroesophageal reflux during infancy. Pediatric Practice Research Group. Pediatrics 102: E67 
6. Nandurkar S \& Talley NJ (2000) Epidemiology and natural history of reflux disease. Bailliere's Clin Gastroenterol 14: 743-757.

7. Rosen R, Vandenplas Y, Singendonk M, Cabana M, DiLorenzo C, et al. (2009) Pediatric gastroesophageal reflux clinical practice guidelines: joint recommendations of the North American Society for Pediatric Gastroenterology, Hepatology, and Nutrition. J Pediatr Gastroenterol Nutr 49: 498-547

8. Jones R, Junghard O, Dent J, Vakil N, Halling K, et al. (2009) Development of the GerdQ, a tool for the diagnosis and management of gastro-oesophageal reflux disease in primary care. Aliment Pharmacol Ther 30: 1030-1038.

9. Jonasson C, Wernersson B, Hoff DA, Hatlebakk JG (2013) Validation of the GerdQ questionnaire for the diagnosis of gastro-oesophageal reflux disease. Aliment Pharmacol Ther 37: 564-572.

10. Zavala-Gonzáles MA, Azamar-Jacome AA, Meixueiro-Daza A, De la Medina AR, Job Reyes-Huerta J, et al. (2014) Validation and diagnostic usefulness of gastroesophageal reflux disease questionnaire in a primary care level in Mexico. J Neurogastroenterol Motil 20: 475-482.

11. Orenstein SR, Shalaby TM, Cohn JF (1996) Reflux symptoms in 100 normal infants: diagnostic validity of the infant gastroesophageal reflux questionnaire. Clin Pediatr 35: 607-614.

12. Orenstein SR1, Cohn JF, Shalaby TM, Kartan R (1993) Reliability and validity of an infant gastroesophageal questionnaire. Clin Pediatr 32: 472-484
13. Nelson SP, Chen EH, Syniar GM, Christoffel KK (1997) Prevalence of symptoms of gastroesophageal reflux during infancy. A pediatric practice-based survey. Pediatric Practice Research Group. Arch Pediatr Adolesc Med 151: 569-572.

14. Kim J, Keininger DL, Becker S, Crawley JA (2005) Simultaneous development of the Pediatric GERD Caregiver Impact Questionnaire (PGCIQ) in American English and American Spanish. Health Qual Life Outcomes 3: 5.

15. Deal L, Gold BD, Gremse DA, Winter HS, Peters SB, et al. (2005) Age-specific questionnaires distinguish GERD symptom frequency and severity in infants and young children: development and initial validation. J Pediatr Gastroenterol Nutr 41: $178-185$

16. Kleinman L, Revicki DA, Flood E (2006) Validation issues in questionnaires for diagnosis and monitoring of gastroesophageal reflux disease in children. Curr Gastroenterol Rep 8: 230-236.

17. Malaty HM, O'Malley KJ, Abudayyeh S, Graham DY, Gilger MA (2008) Multidimensional measure for gastroesophageal reflux disease (MM-GERD) symptoms in children: A population-based study. Acta Paediatr 97: 1292-1297.

18. Remes-Troche JM, Rodríguez-González B, Valdovinos-Díaz MA (2006) La enfermedad por reflujo gastroesofágico en México. Revisión sistemática. Rev Gastroenterol Mex 71: 151-159. 